\title{
Underground Energy Storage Utilizing Concrete Building Foundation: Experimental and Numerical Approach
}

\author{
M. M. Mousa ${ }^{1 *}$, A. M. Bayomy ${ }^{1}$, J. Wang ${ }^{2}$, S. B Dworkin ${ }^{1}$, M. Z. Saghir ${ }^{1}$ \\ ${ }^{1}$ Department of Mechanical and Industrial Engineering, Ryerson University, 350 Victoria St, Toronto \\ ${ }^{2}$ McClymont and Rak Engineers Inc, 111 Zenway Blvd, Woodbridge, ON, Canada \\ *corresponding author:mmousa@ryerson.ca
}

\begin{abstract}
Space heating and cooling represents $63 \%$ of total building energy demand. In the present study, the concept of concrete foundation piles was used as an underground storage medium. This system requires no additional drilling costs or space, unlike conventional boreholes. A lab-scaled experiment facility was designed to experimentally investigate the thermal response of a concrete pile during the charging and discharging processes. The amount of energy stored and released during each process was evaluated. A flow rate parametric study was also conducted to explore the effect of the laminar and turbulent flow behaviour. In order to complement the experimental study, an extensive CFD model was developed and compared with the experimental data. There was good agreement between the numerical and experimental results for each process at different flow rates. The results revealed that increasing the flow rate increases not only the heat rejection and extraction but also the storage efficiency.
\end{abstract}

Keywords: borehole, energy pile, thermal storage, thermal response, ground source heat pump 


\section{Nomenclature}

Greek symbols

$\begin{array}{ccc}A & \text { Area }\left(\mathrm{m}^{2}\right) & \rho \\ C_{p} & \text { Specific heat }\left(\mathrm{J} / \mathrm{kg} \cdot{ }^{\circ} \mathrm{C}\right) & \mu \\ d & \text { Diameter }(\mathrm{m}) & \sigma_{X} \\ f & \text { Fanning friction factor } & \delta \\ k & \text { Thermal conductivity } & \text { Subscripts } \\ & \text { (W/m.K) } & \\ N u & \text { Nusselt number } & s \\ P r & \text { Prandtl number } & l \\ Q & \text { Volumetric flow rate (ml/min) } & \text { Abbreviations } \\ q & \text { Heat transfer rate }(\mathrm{w}) & \mathrm{CFD} \\ R e & \text { Reynolds number } & \text { COP } \\ T & \text { Temperature }\left({ }^{\circ} \mathrm{C}\right) & \text { Exp } \\ t & \text { Time (s) } & \text { GSHP } \\ U & \text { Velocity fields vector (m/s) } & \text { HDPE } \\ V & \text { Average velocity (m/s) } & \text { HEX } \\ \bar{x} & \text { Best value } & \text { Num } \\ & & \text { PVC } \\ & & \end{array}$

Th

\author{
Density $\left(\mathrm{kg} / \mathrm{m}^{3}\right)$ \\ Dynamic viscosity (Pa.s) \\ Standard deviation \\ Uncertainty
}

Solid

Liquid
Computational fluid dynamics

Coefficient of performance

Experimental

Ground source heat pump

High-density polyethylene

Heat exchanger

Numerical

Polyvinyl chloride

Thermocouple 


\section{Introduction}

Nowadays, rapid increases in energy demand and greenhouse gas emission rates represent a big challenge. Most energy production is still dependent on conventional fuel as an energy source. Not only are these sources not renewable, they also increase greenhouse gas emission rates. According to the 2015 Paris climate meeting, 130 countries have agreed that the current level of carbon dioxide is catastrophic and must be decreased[1]. Canada's nationally determined Contribution to the Paris Agreement on climate change is to reduce annual emissions to 30 percent below 2005 levels by the year 2030, Canada has reported in December 2019 that with additional measures scenario, emissions are projected to be only $19 \%$ below 2005 levels [2].

Energy costs have increased rapidly in the past few years, calling attention to energy consumption and energy-efficient systems. One of the highest energy consumers is the residential building sector, which represents $30 \%$ of the total energy consumption around the world. In countries such as the United States and the United Kingdom, the numbers are closer to $40 \%$ [3]. Residential energy consumption is also the source of over $30 \%$ of total greenhouse gas emissions to the atmosphere[3].

\subsection{Energy piles and boreholes}

Today, many research studies are focused on using building piles to develop ground source heat pumps [4]. Austria was the first country to use the ground source heat pump [4]. By 2017, there were approximately 100,000 units installed around the country, and today, 78 countries around the world are using ground source heat pumps[5]. The number of ground source heat pumps has increased by $215 \%$ between 2005 and $2010[6]$.

The ground source heat pump gained this popularity due to its high coefficient of performance and low running cost. One conventional GSHP type is the borehole system, which consists of two primary sections: the conventional heat pump and the ground heat exchanger. The vertical type of heat exchangers is the most common type, due to its high-performance level [6-7]. Normally, the heat exchanger is inserted into a hollow concrete cylinder, and the rest of the hole is backfilled with grout, which usually consists of either bentonite or quartz with sand, or a water mixture. Each backfilling material has its own merits. Quartz offers high thermal conductivity, while bentonite offers high sealing features [8-9]. High-Density Polyethylene (HDPE) is the most common material for the heat exchanger tubes, with a single or double u-tube configuration [11].

The working fluid that transfers the energy from/to the heat pump to/from the ground heat exchanger is usually water. In cold areas, an antifreeze mixture is used to prevent the freezing of water inside the heat exchanger tube. While borehole systems have proven their ability to boost the performance of conventional heat pumps, they are not without limitations. These include the lack of drilling space in residential areas, the unbalanced heating and cooling load throughout the year according to the dominant load, and the high initial cost of drilling.

The concept of energy piles is based on the use of underground soil as a thermal storage unit. This is achieved by implementing a Heat Exchanger (HEX) inside the pile's concrete shell. The HEX is coupled with a conventional ground heat pump using a circulating fluid. The working fluid transfers the heat between the condenser of the heat pump and the underground HEX. The heat is then transferred to the concrete shell, which passes it to the nearby underground soil. Therefore, during the summer season, the conventional heat pump transfers the heat from the lower temperature side (evaporator), to the higher temperature side (condenser). Then, the working fluid carries the rejected heat at the condenser to the ground HEX and finally to the soil. The dissipated energy from the concrete shell to the underground soil 
throughout the season increases the average temperature of the underground soil. This cycle can then be inverted during the winter season. In addition, energy piles can be coupled with a solar collector to store solar energy during the summer season or during the daytime during the winter season.

One of the terminal gates of the Zurich airport, built in 2003, has 306 concrete piles in its foundation design. Those foundation piles were used as energy piles, to supply the terminal gate with cooling and heating loads, and the energy piles provide $85 \%$ of the total heating load[12]. The remainder of the heating is provided by heaters at the peak load. If, for any reason, the energy piles were unable to meet the cooling load, the heat pump would be reversed to supply the additional cooling load [12].Hokkaido, Japan, also houses a two-story building that makes use of 26 energy piles at a depth of $9 \mathrm{~m}$ for heating, and the measurements taken during the 1999-2000 winter season revealed 18.3 MWh of heat and a coefficient of performance of 3.9 [13].

Although energy piles and boreholes serve the same function, energy piles are superior. This is because boreholes require an empty space for drilling and installation of the borehole system while the building foundation piles are used in energy pile systems, removing the need for empty space and the cost of the drilling itself. Lastly, in borehole systems, the borehole must be backfilled with grout. In energy pile systems, the heat exchanger is completely covered with concrete paste, which enhances the heat transfer rate and reduces the total cost. Although there will be variability in the temperature of the foundation piles, which could cause expansion or contraction in the pile dimensions, the ratio of expansion or contraction will not affect the building structure [14].

\subsection{Energy pile design}

The design of the energy pile field is restricted by the structural design of the building, as the location, diameter, and depth of each energy pile are mainly designed for load bearing. Therefore, thermal interference is expected to occur between the closely located piles[4],[15]. The following table summarizes the different designs of HEX tubes found on literature studies for boreholes and energy piles, which will guide to present the HEX design on the current study.

Table 1: heat exchanger configuration and tube materials

\begin{tabular}{|c|c|c|c|c|c|c|c|c|}
\hline Author & GSHP type & Pipe material & U-tube & 2 U-tube & 3 U-tube & W shape & Coaxial & Spiral \\
\hline You et al. [16] & Energy pile & HDPE & & & & $\nabla$ & & \\
\hline Hamada et al.[22] & Boreholes & - & $\nabla$ & $\nabla$ & & $\nabla$ & $\nabla$ & \\
\hline Zhao et al.[14] & $\begin{array}{l}\text { Borehole/ } \\
\text { energy pile }\end{array}$ & HDPE & & $\nabla$ & & & & $\nabla$ \\
\hline Gao et al.[20] & Energy pile & HDPE & $\nabla$ & $\nabla$ & $\nabla$ & $\nabla$ & & \\
\hline Yoon et al.[23] & Energy pile & polybutylene & & & & $\nabla$ & & $\nabla$ \\
\hline Gao et al.[17] & energy pile & HDPE & $\nabla$ & $\nabla$ & $\nabla$ & $\nabla$ & & \\
\hline Park et al. [23] & Energy pile & polybutylene & & & $\nabla$ & $\nabla$ & & \\
\hline Zarrella et al. [24] & Energy pile & - & & & $\nabla$ & & & $\nabla$ \\
\hline $\begin{array}{l}\text { Jalaluddin et } \\
\text { al.[19] }\end{array}$ & Energy pile & $\begin{array}{l}\text { stainless, } \\
\text { polyvinyl } \\
\text { chloride and } \\
\text { polyethylene }\end{array}$ & $\nabla$ & $\nabla$ & & & $\nabla$ & \\
\hline Wood. et al. [21] & Energy pile & - & $\nabla$ & & & & $\nabla$ & \\
\hline
\end{tabular}


In the previous studies spiral tube HEX was found to have a higher heat transfer rate than double U-tube HEX [14] and W-tube HEX[18]. While triple U-tube HEX was found to have a higher heat transfer rate than double U-tube and single U-tube [20]-17], and higher than that of W-tube HEX [20]17],[23].Jalaluddin et al. [19] found that increasing the flow rate of the working fluid from $2 \mathrm{l} / \mathrm{min}$ to 4 $1 /$ min led to an increase in the amount of heat transferred. They only found a slight increase in the amount of heat transferred after increasing the flow rate from 4 1/min to $81 / \mathrm{min}$. Cecinato et al. [25]also concluded that increasing the flow rate of the working fluid does not significantly impact the performance of the piles. They concluded that it is adequate to have a turbulent flow inside the heat exchanger tubes. Gao et al. [17] found that increasing the flow rate of a W-shaped heat exchanger from $0.171 \mathrm{~m}^{3} / \mathrm{h}$ to $0.342 \mathrm{~m}^{3} / \mathrm{h}$ increased the average heat rejection rate by $49 \%$, while increasing the flow rate from $0.342 \mathrm{~m}^{3} / \mathrm{h}$ to $0.684 \mathrm{~m}^{3} / \mathrm{h}$ only increased the average heat rejection rate by $11 \%$. The study concluded that a higher flow rate is not efficient due to the pressure drop and pumping costs.

None of the previously mentioned studies used a 4 U-loop HEX. So, in the present study a 4 U-loop copper heat exchanger was inserted inside a lab-scaled concrete foundation pile to investigate its ability to work as a ground source heat pump system, known as 'energy piles'. A 4-U tube HEX is easy to manufacture and install within the presented sample dimension $(30 \mathrm{~cm} \times 10 \mathrm{~cm})$ than that of spiral HEX. Also, in the present study, the underground soil was replaced with 3 layers of insulation to study the effect on the concrete pile. The second paragraph in section 2.1 showed a comparison between the different types of HEX configuration. The study was conducted experimentally and numerically, and it includes an investigation of the thermal response of the pile during charging and discharging, the amount of energy stored and released during each process and the effect of flow behaviour (laminar or turbulent) on the storage efficiency of the pile, The work aim to present the effect of the flow rate on the thermal behavior, the storage capacity, and the storage efficiency of the concrete pile itself. In this paper, section 2 presents the experimental setup followed by the uncertainty analysis in section 3 . Section 4 focuses on the numerical model description. Finally, the results and discussions are in section 5.

\section{Experimental setup}

\subsection{Experimental description}

An experimental setup was designed to mimic a scaled building foundation pile. The experimental setup dimensions were $30 \mathrm{~cm}$ depth and a $10 \mathrm{~cm}$ diameter, with 16 steel bars. Steel bars of $3.6 \mathrm{~mm}$ in diameter were used. Figure 1 shows the main components of the experiment as follow: Data Acquisition (DAQ), 4 U-shaped HEX inserted inside the concrete cylinder, a water bath, a turbine flowmeter, a control valve, connecting tubes, data processing software and 10 thermocouples (inlet, outlet, surface, ambient and 6 locations inside the concrete). 


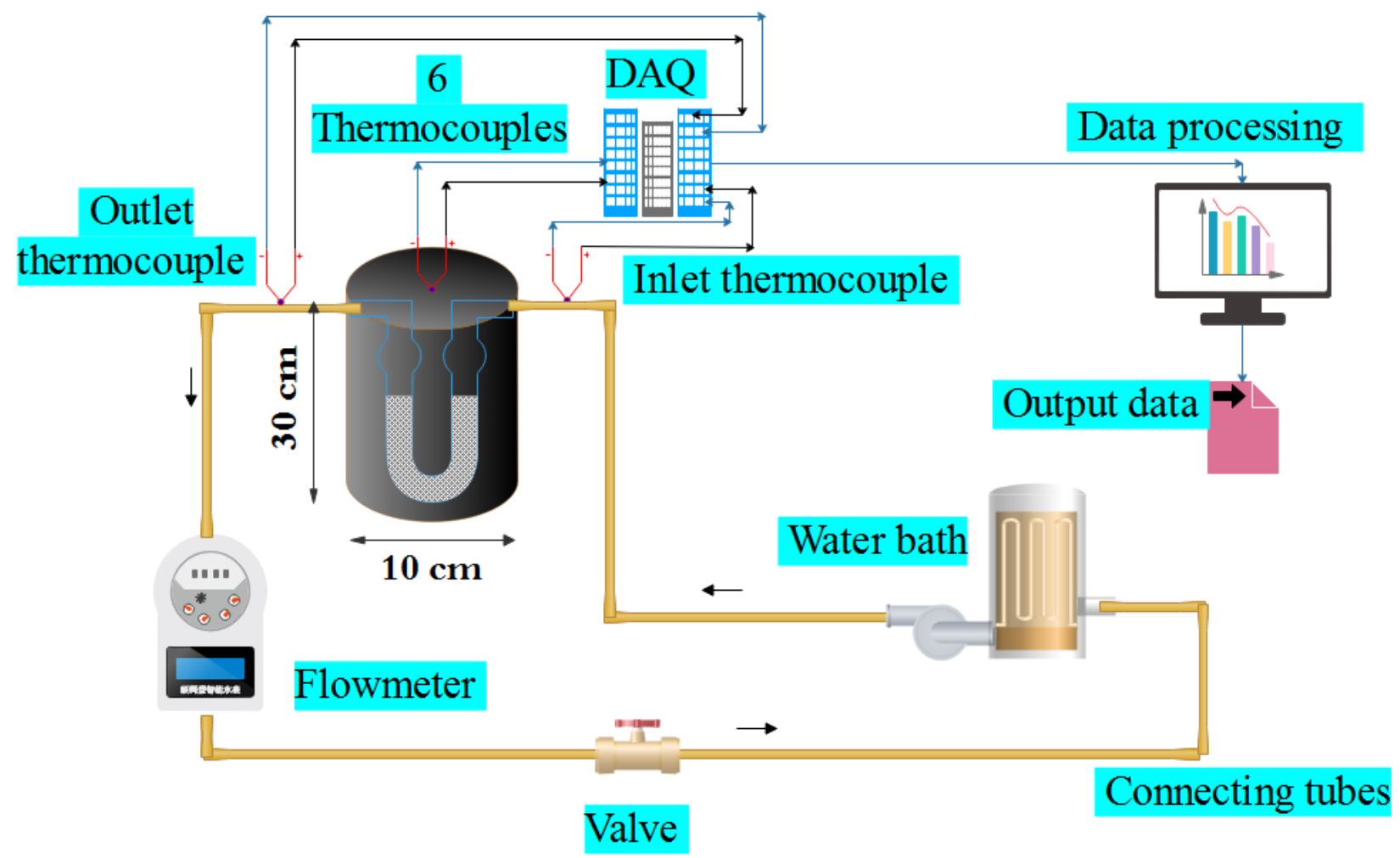

Figure 1:Experiment flow diagram

The first step was to bond the steel cage inside the mold base. The original steel bars were 1.5 meters in length and each bar was divided into five $30 \mathrm{~cm}$ portions. One of the ends of each portion was then heated to penetrate the plastic cup of the mold. After fixing all of the steel bars into the mold base, the steel bars were connected to a circular copper ring to maintain the circular shape of the steel bar distribution, as shown in Figure 2 (a). The next step was to insert the four U-loop tubes into the circular steel cage which was then fastened into the cage. To avoid any significant thermal short circuits due to contact between tubes with different temperature, the inlet of each U-loop was designed to be attached to the inlet of the next U-loop. The same is true for the exit of each U-loop, and a small distance left between HEX legs to allow space for tubes and clamps as shown in Figure 2 (b). 


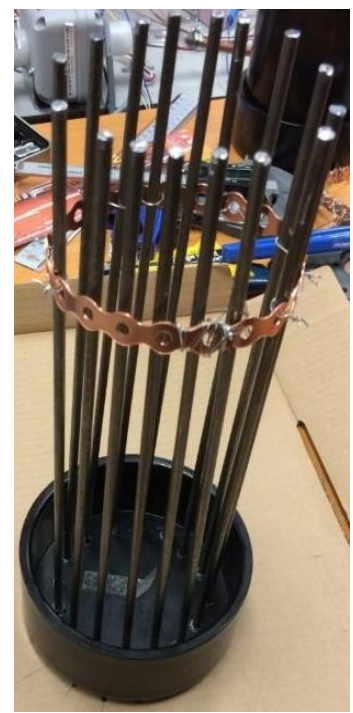

(a) Re-bare cage

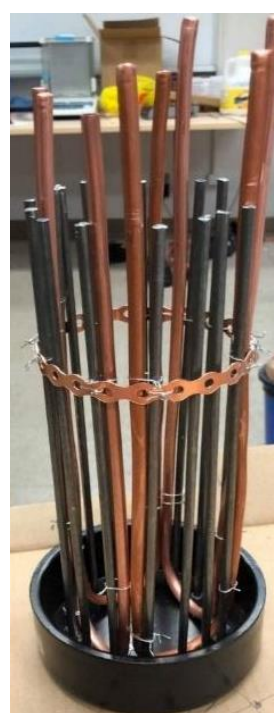

(b) Re-bare cage with u-loops

Figure 2: Experimental rebar cage

The thermocouples were then plugged into the sample. The expectation was that the sample would be symmetric along the yellow and red lines, as shown in Figure 3. In order to measure the temperature distribution across these lines, three thermocouples were used in each line, the location of each thermocouple is shown in the figure. All of the thermocouples were at a depth of $15 \mathrm{~cm}$ from the top of the concrete sample (so as to be in the middle of the concrete sample). Thermocouples 1, 2, and 3 were at radii of $0 \mathrm{~mm}, 14 \mathrm{~mm}$, and $28 \mathrm{~mm}$, respectively. The use of a fourth thermocouple at a radius of $42 \mathrm{~mm}$ was planned, but the re-bar cage and the heat exchanger prevented the fastening of that thermocouple without making contact with the heat exchanger tubes.

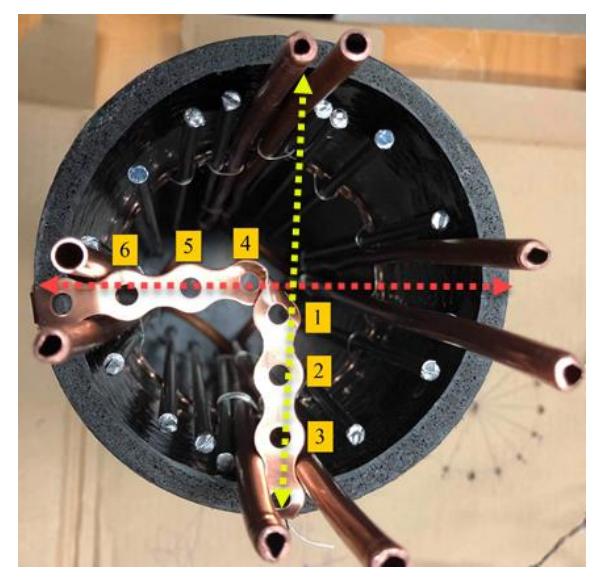

Figure 3: Symmetry lines and thermocouples locations

A concrete paste with a water-weight-per-cement-weight ratio(w/c) of 0.5 was then poured into the sample, as shown Figure 4(a), and left for 7 days to completely solidify. After the solidification process, the sample was ready to be connected with the water tubes, inlet and exit thermocouples, and the flow meter. The inlet tube was divided into two branches and each branch was divided into two $6.35 \mathrm{~mm}$ tubes to supply the inlet flow rate of water. The same was done for the exit tubes. The inlet and outlet thermocouples were located $20 \mathrm{~cm}$ away from the tube's inlet and outlet, respectively. 
The last step was the insulation process. A $20 \mathrm{~cm}$ heavy-duty cardboard with a height of $40 \mathrm{~cm}$ was used to contain the entire sample $(30 \mathrm{~cm})$ with $5 \mathrm{~cm}$ extra on the top and bottom. The insulation used was spray foam insulation suitable for gaps of $7.5 \mathrm{~cm}$ or less. After 3 days, the sample was ready for testing, as shown in Figure 4(b).

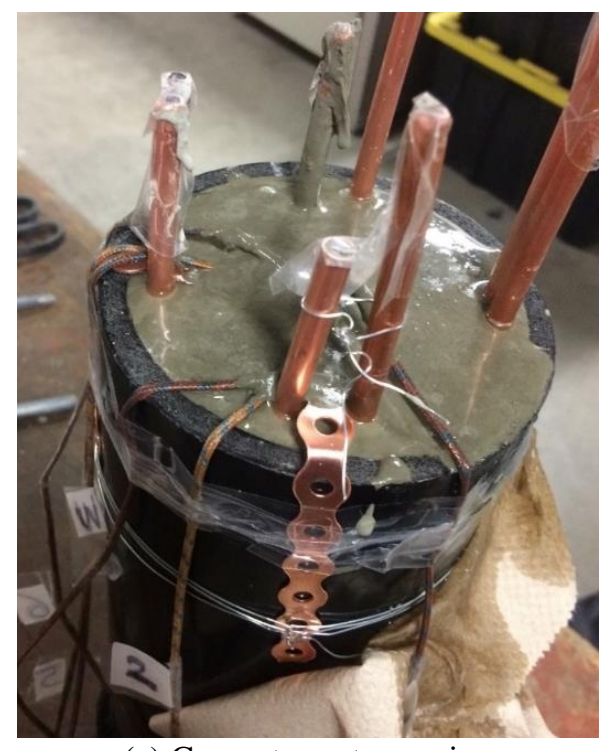

(a) Concrete paste pouring

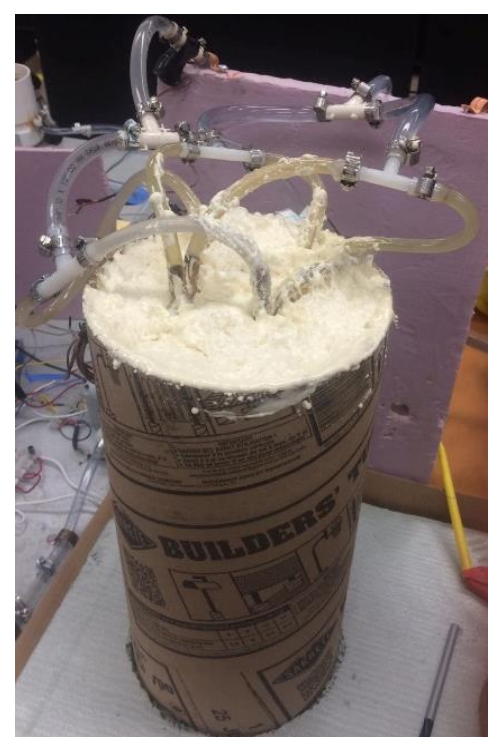

(b) Sample with insulation

Figure 4: Concrete pouring and insulating processes

\subsection{Experimental procedure}

The primary objective of the present study was to determine the thermal behaviour of a real energy pile storage system. It is important to note that the average initial temperature of all the 6 thermocouples inside the concrete was around $8.7^{\circ} \mathrm{C}$ corresponding to the ground temperature range of soil in Ontario, Canada, which is between 8 and $10^{\circ} \mathrm{C}$ [26]. The concrete pile was cooled down from the ambient temperature $\left(20^{\circ} \mathrm{C}\right.$ $\pm 2^{\circ} \mathrm{C}$ ) to the required initial temperature by passing water through the heat exchanger from a water-bath, at which the water initial temperature was $\left(18^{\circ} \mathrm{C} \pm 2{ }^{\circ} \mathrm{C}\right)$, and it decreased gradually to reach $8.7^{\circ} \mathrm{C}$.the water-bath was connected to the sample with clear polyvinyl chloride (PVC) tubes with $9.5 \mathrm{~mm}$ diameter.

After the precooling process, the heating process was initiated. The desired maximum heating temperature was $35^{\circ} \mathrm{C}$. This temperature was used to investigate the ability of the energy pile to be coupled not only with the cooling/heating system, but also with a solar energy system. The water-bath provides a more realistic simulation of the actual process of the energy pile storage system, as the coupled heat pump outlet water temperature increases gradually at the beginning of the summer season. In addition, if the system was coupled with a solar collector system, the solar collector output water temperature would gradually increase during the day time to reach the peak value, then decrease again during night time.

The charging process time period was 1.5 hours and the cooling process started immediately by changing the set-point temperature from $35^{\circ} \mathrm{C}$ to $6^{\circ} \mathrm{C}$. Although the response of the water-bath to heating was faster than its response for cooling, the discharging process also lasted for 1.5 hours.

In a real borehole design, the flow rate in the underground HEX for 1 ton of refrigeration is 3 gallons per minute [27]. The calculations were based on the same Reynolds number inside a real tube with a diameter of $3.4 \mathrm{~cm}$ and an experimental tube with a diameter of $0.425 \mathrm{~cm}$. The experimental flow rate was calculated to be $1471 \mathrm{ml} / \mathrm{min}(0.3822$ gallons per minute). 


\section{Uncertainty analysis}

The experimental procedure was conducted 3 times for a flow rate of $1471 \mathrm{ml} / \mathrm{min}$ in order to analyse the random error associated with all 10 thermocouples used to measure the temperature at 10 different locations. All of the thermocouples used were of type $\mathrm{k}$, with an error of $0.75 \%$, which was considered a systematic error at all of the thermocouples. The random error calculations were obtained by using the Taylor method [28] as follows:

If $\mathrm{x}_{1}, \mathrm{x}_{2}, \ldots \ldots \ldots, \mathrm{x}_{\mathrm{N}}$ denote $\mathrm{N}$ separate measurements of one quantity $\mathrm{x}$, then we define

$$
\begin{gathered}
\bar{x}=\frac{1}{N} \sum_{i=1}^{N} x_{i} \\
\sigma_{X}=\sqrt{\frac{1}{N-1} \sum_{i=1}^{N}\left(x_{i}-\bar{x}\right)^{2}}
\end{gathered}
$$

And the random error will equal to $\sigma_{X}$, while the combined error will equal to the sum of systematic error and the random error.

The max uncertainty for each thermocouple was as the following:

Table 2: Maximum uncertainty values at each location

\begin{tabular}{cccc}
\hline Thermocouple number & $\begin{array}{c}\text { Radius }(\mathrm{mm}) / \\
\text { Function }\end{array}$ & $\begin{array}{c}\text { Max } \\
\text { uncertainty }\left({ }^{\circ} \mathrm{C}\right)\end{array}$ & $\begin{array}{c}\text { Percentage of } \\
\text { reading }\end{array}$ \\
\hline Th1(Thermocouple\#1) & 0 & 0.364075 & $1 \%$ \\
Th2(Thermocouple\#2) & 14 & 0.394986 & $1.1 \%$ \\
Th3(Thermocouple\#3) & 28 & 0.424844 & $1.2 \%$ \\
Th4(Thermocouple\#4) & 0 & 0.355115 & $1 \%$ \\
Th5(Thermocouple\#5) & 14 & 0.370302 & $1 \%$ \\
Th6(Thermocouple\#6) & 28 & 0.417976 & $1.2 \%$ \\
Th7(Thermocouple\#7) & Inlet & 0.464656 & $1.3 \%$ \\
Th8(Thermocouple\#8) & Outlet & 0.43654 & $1.2 \%$ \\
Th9(Thermocouple\#9) & Surface & 0.436444 & $3 \%$ \\
Th10(Thermocouple\#10) & Ambient & 0.811249 & $3.3 \%$ \\
\hline
\end{tabular}

For the propagation of uncertainty to the value of heat transfer rate, the following Taylor method [28] has been used:

$$
\delta q=\sqrt{\left(\frac{\partial q}{\partial \Delta T} \delta \Delta T\right)^{2}+\left(\frac{\partial q}{\partial Q} \delta Q\right)^{2}}
$$

Where $\delta q$ is the uncertainty in heat transfer rate, $\Delta \mathrm{T}$ is the temperature difference between inlet and outlet and $\mathrm{Q}$ is the volumetric flow rate of the flow meter. The accuracy of the turbine flow meter was $\pm 6 \%$ and the total uncertainty was calculated to be $11 \%$ 


\section{Numerical Model Description}

The numerical results were obtained using the finite element technique [29]in order to allow for a comparison with the experimental results.

\subsection{Governing Equations}

In this study, the three-dimensional numerical model was created by using the finite elements techniques (COMSOL Multiphysics) for the experimental setup. Four U-loop heat exchangers were placed into concrete, wherein this 4 U-loop was characterized with outer and inner diameters given to be $6.35 \mathrm{~mm}$ and $4.35 \mathrm{~mm}$, respectively. Figure 5 (a) shows the four main layers which have been used to simulate material surrounding the U-loops. The layers consist of a concrete material layer, PVC layer, insulation material layer, and heavy-duty cardboard material layer. Table 3 gives a summary of the thermal properties of each of the layers. It should be noted as well that a tetrahedral element was utilized in describing the numerical domain as shown in Figure 5(b), and an analysis of grid independence was conducted.

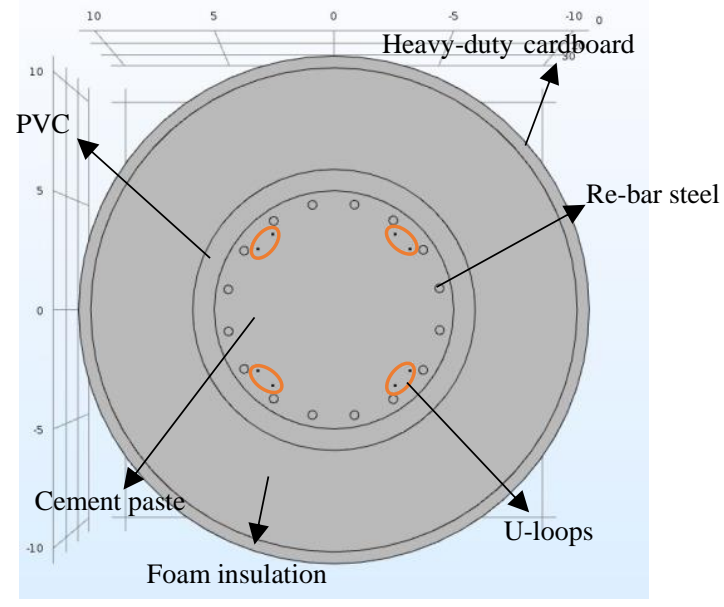

(a)

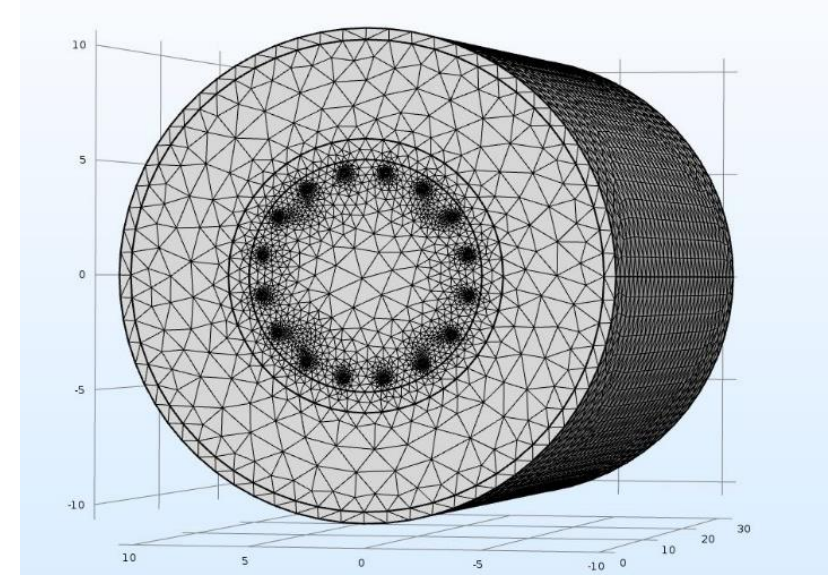

(b)

Figure 5:Model geometry and meshing

Table 3:Layer properties [29][30][31][32]

\begin{tabular}{cccc}
\hline Material & Density $\left(\mathbf{k g} / \mathbf{m}^{\mathbf{3}}\right)$ & $\begin{array}{c}\text { Thermal Conductivity } \\
(\mathbf{W} / \mathbf{m . K})\end{array}$ & Specific heat $(\mathbf{k J} / \mathbf{k g . K})$ \\
\hline Foam insulation & 35 & 0.024 & 1.45 \\
Cement paste & 1500 & 0.7 & 0.7 \\
PVC & 1380 & 0.19 & 1 \\
heavy-duty cardboard & 900 & 0.21 & 1.88 \\
Re-bar steel & 7850 & 44.5 & 457 \\
Copper & 8960 & 401 & 385 \\
\hline
\end{tabular}

Using these assumptions, a system of governing equations was obtained to describe the heat transfer and fluid flow through the U-loop HEX. The current problem involves the interaction between the fluid flow of the heat transfer fluid (e.g. water) and the thermal energy transfer and storage through the concrete. The equations are as follows:

Energy conservation equations inside solid domains (e.g. concrete): 


$$
\left(\rho c_{p}\right)_{s}\left(\frac{\partial T}{\partial t}\right)=k_{s}\left(\frac{\partial^{2} T}{\partial x^{2}}+\frac{\partial^{2} T}{\partial y^{2}}+\frac{\partial^{2} T}{\partial z^{2}}\right)
$$

Nusselt number inside the U loop HEX is obtained as follow [33]:

$$
\begin{array}{cl}
N u_{D}=0.023 \operatorname{Re}_{D}^{4 / 5} \cdot \operatorname{Pr}^{n} & \text { (Turbulent Flow) } \\
N u_{D}=3.66 & \text { (Laminar Flow) }
\end{array}
$$

In the above equations $\rho_{s}$ is density of solid layers (e.g. concrete), $c_{p_{s}}$ is specific heat of solid, $U(u, v, w)$ is the velocity field vector, $T$ is the temperature, $k_{S}$ is thermal conductivity of solid, $N u_{D}$ is Nusselt number, $R e_{D}$ is Reynolds number, $P r$ is Prandtl Number, and $n$ is a constant given to be 0.4 for cooling and 0.3 for heating.

Fluid Flow Model:

$$
\left(\rho_{l} A C_{p l}\right) \cdot \frac{\partial T}{\partial t}+\left(\rho \cdot A \cdot C_{p l}\right) U \cdot \nabla T=\nabla \cdot\left(A \cdot k_{l} \cdot \nabla T\right)+\frac{1}{2} f \cdot \frac{\rho A}{d}|U| U^{2}
$$

Where $\rho_{l}$ is liquid's density, $c_{p_{l}}$ is liquid's specific heat, $k_{l}$ is liquid's thermal conductivity, $f$ is the friction factor of the U-loop HEX tube and $A$ is the cross-section area of the U-loop HEX tube. The convergence criterion at each iteration is set as follows: at every iteration, the average relative error of $U$ and $T$ are computed. These are obtained via the following relation:

$$
R=\frac{1}{n \cdot m} \sum_{i=1}^{i=m} \sum_{j=1}^{j=n}\left|\frac{\left(F_{i, j}^{\mathrm{s}+1}-F_{i, j}^{s}\right)}{F_{i, j}^{\mathrm{s}+1}}\right|
$$

where $\mathrm{F}$ represents one of the unknowns, viz., $u, v, w$, or $T$ and $\mathrm{s}$ is the iteration number and $(\mathrm{i}, \mathrm{j})$ represents the co-ordinates on the grid. Convergence is reached if $R$ for all the unknowns is below $1 \times 10^{-6}$ in two successive iterations.

\subsection{Boundary and initial conditions}

At the beginning of each experiment, for any flow rate, the average initial temperature at any point inside the concrete portion was approximately $8.7^{\circ} \mathrm{C}$. The inlet water temperature profile was nearly the same as shown in Figure 6 (a). The ambient temperature profile for all of the experiments was as shown in Figure 6 (b), with an average temperature of approximately $22 \pm 0.5^{\circ} \mathrm{C}$. All the previous conditions were used as input data for the numerical model. 


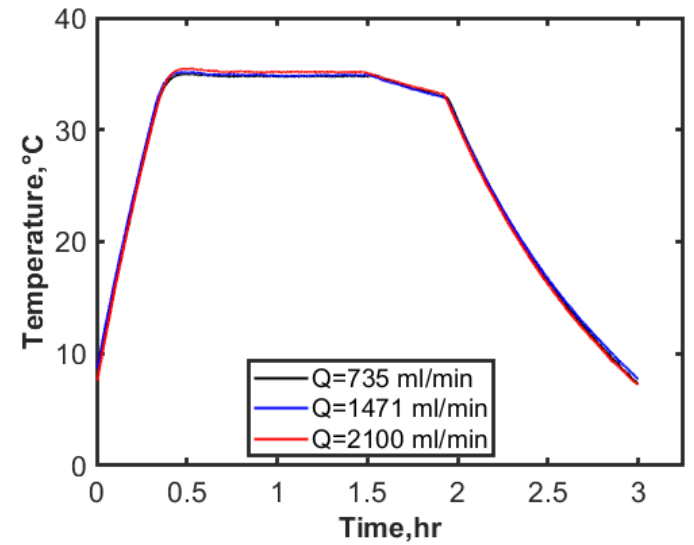

(a) Inlet temperature profile at each flow rate

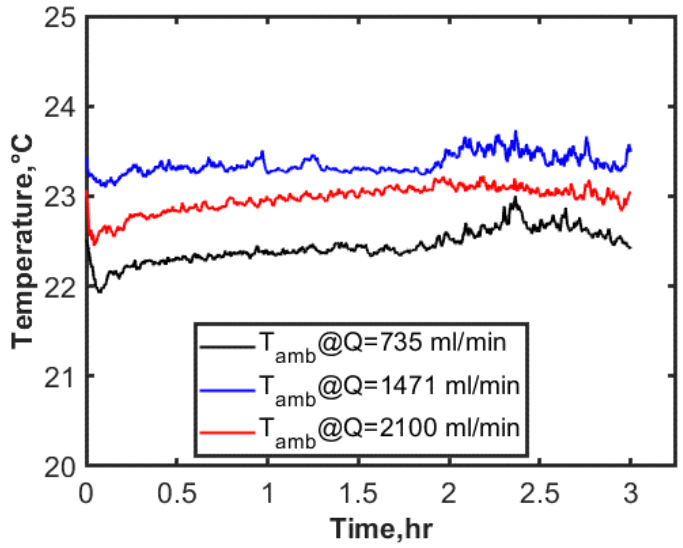

(b) Ambient temperature profile at each flow rate

Figure 6: Inlet and ambient temperature during each flow rate

\subsection{Mesh Independence Analysis}

In the present finite element study, a tetrahedral element was used to describe the numerical domain. In order to examine the grid sensitivity, the maximum outlet water temperature was predicted over the outlet surface of the HEX leg for different numbers of domain elements, as shown in Figure 7. The number of elements used was $1,500,916$ and the relative error variation was less than 0.015 .

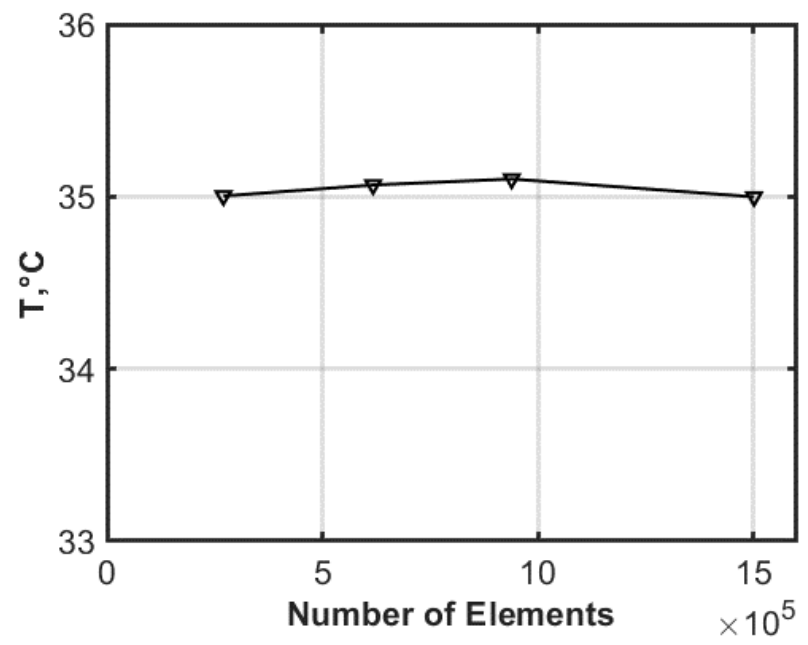

Figure 7: Mesh independence analysis

\section{Results and Discussion}

\subsection{Outlet water temperature}

Figure 8 (a) shows the experimental inlet and outlet water temperatures versus time. As the figure shows, at the beginning of the charging process, there is almost no difference between the inlet and outlet temperatures. As previously mentioned, the temperature of the inlet water increased gradually from $8.7^{\circ} \mathrm{C}$ to $35^{\circ} \mathrm{C}$. Then, as the inlet water temperature increased, the difference between the inlet water and outlet water temperature could be clearly seen.

After around 1/2 hr. of charging, the inlet temperature became nearly stable and the difference between the inlet and outlet temperatures reached its maximum value. At this point the temperature of the concrete 
sample was increasing and the heat transfer rate between the water and the concrete sample began to decrease. This could be seen during the period from $1 / 2 \mathrm{hr}$. to $2 \mathrm{hr}$. The charging process was terminated after $1 \frac{1 / 2}{\mathrm{hr}}$. and the discharging process was started. However, the temperature difference inverted after around $2 \mathrm{hr}$. due to the response of the water-bath.

At the beginning of the discharging process, the temperature difference was almost zero and the water-bath started to cool down the inlet water temperature using fans only. The refrigeration system was then turned on and the inlet water temperature began to decrease rapidly until the end of the discharging process at 3 hr.

Figure 8 (b) illustrates the experimental and numerical outlet water temperatures versus time during the charging and discharging processes. The figure shows that the numerical predictions are in line with the experimental data. However; there was a variation in temperature difference between the inlet and outlet temperature experimentally and numerically. The cause of this variation could be referred to two reasons (i) the distance between the inlet thermocouple and the sample (ii) the branching of the inlet tube to four different tubes and the same at the outlet tubes

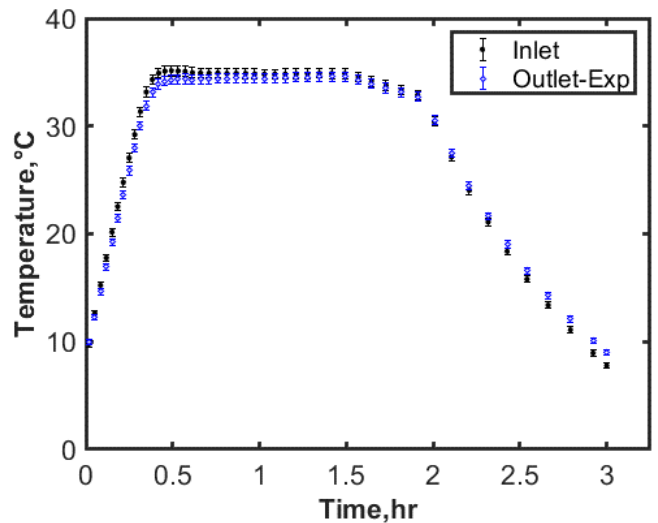

(a) Experimental inlet and outlet temperature profile

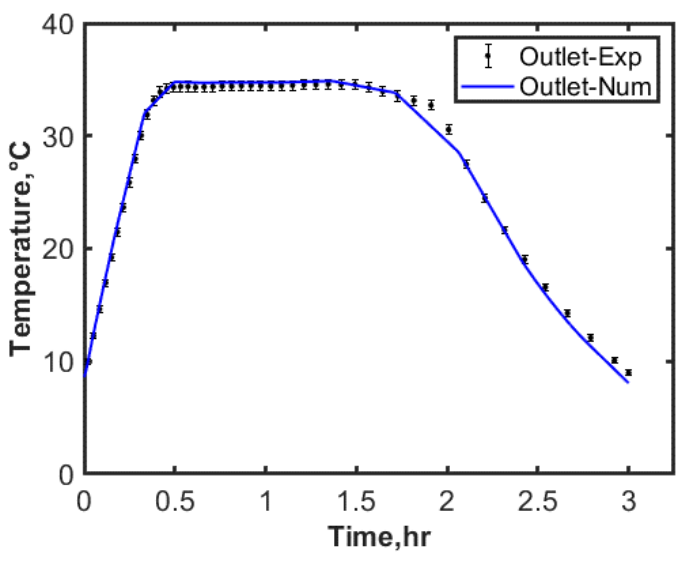

(b) Experimental and numerical outlet temperature profile

Figure 8:Inlet and outlet water temperature for $\mathrm{Q}=1471 \mathrm{ml} / \mathrm{min}$

\subsection{Temperature distribution along the radius of the sample}

Figure 9 shows an isometric view of the experimental temperature distribution along the radius of the concrete sample at any time during the charging and discharging processes. The three vertical lines represent the temperature variation at each thermocouple with time, while the horizontal lines represent the temperature slope at each time step. As the figure shows, at the beginning of the charging process, the temperature slope was negligible, as the working fluid and the concrete were initially at the same temperature. After the charging process was underway, the temperature slope changed to allow the heat transfer from the heat exchanger to the centre of the sample. At the end of the charging process, the temperature slope became negligible again, as the temperature at all the points reached its maximum and the heat transfer between the heat exchanger tubes and the concrete was discontinued. The discharging process was then initiated. As the figure shows, the temperature slope was gradually inverted to allow the heat extraction during the discharge process.

The figure also shows that the final temperature distribution of the sample, at the end of the discharging process, wasn't the same as the temperature distribution at the beginning of the charging process. This 
indicates that the amount of heat input during the charging process wasn't the same as the amount of heat extracted during the discharging process. These amounts are discussed briefly in the storage efficiency section.

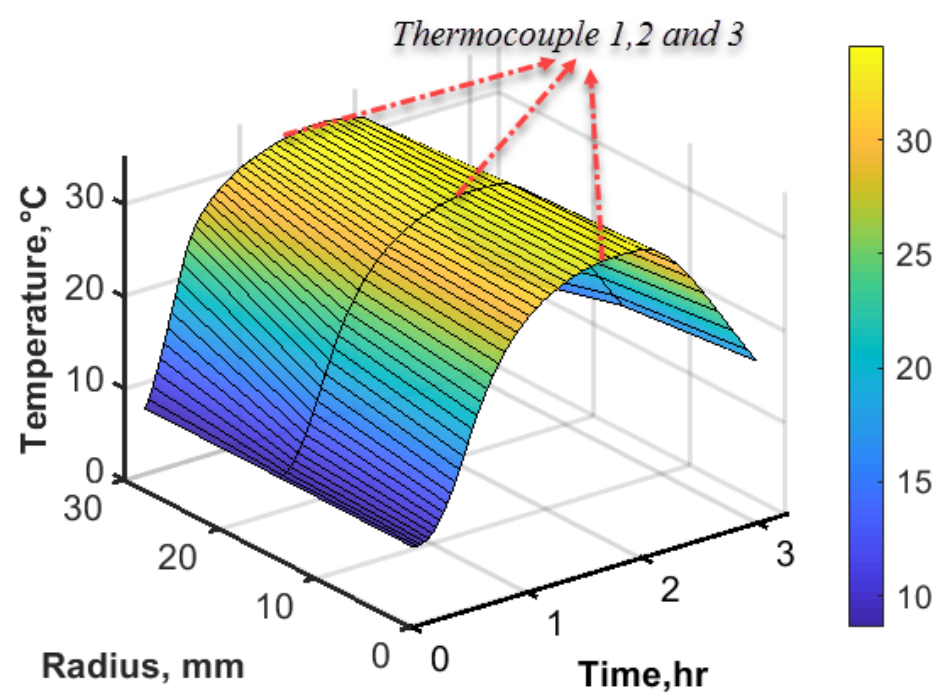

Figure 9: Temperature slope along the radius with time $\mathrm{Q}=1471 \mathrm{ml} / \mathrm{min}$

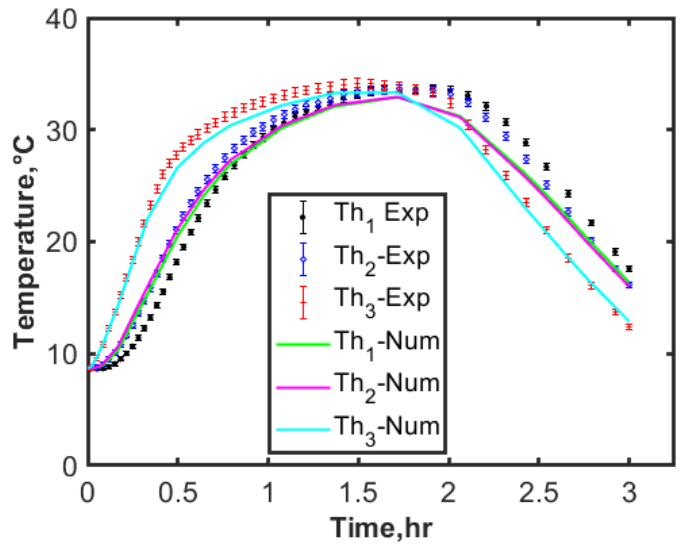

(a) Thermocouples 1,2 and 3 (first symmetry line)

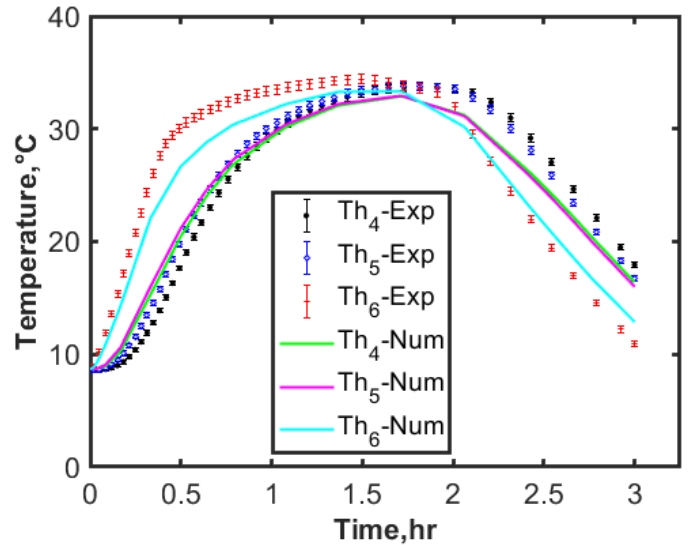

(b) Thermocouples 4,5 and 6 (second symmetry line)

Figure 10:Experimental and numerical temperature variation with time $\mathrm{Q}=1471 \mathrm{ml} / \mathrm{min}$

Figure 10 reveals the temperature profile at each of the six thermocouples numerically and experimentally. As shown, the numerical predictions of concrete's thermal response were in line with the experimental results. Although, the numerical predictions showed that the sample is $1 / 4$ symmetrical, there were a small variations experimentally between the thermocouples located at the same radius i.e. (thermocouple 3 and thermocouple 6).This may occurred due to the deviation of the thermocouple's location during the experimental setup and/or the movement of their tips during the concrete pouring.

Although the charging process was terminated after $1 \frac{1 / 2}{\mathrm{hr}}$, Figure 10 revealed that the temperature of thermocouples 1 and 4 continued to increase until around $2 \mathrm{hr}$. This trend is caused by the transitional heat transfer inside the sample. When the discharging process was initiated, the concrete volume between the heat exchanger tubes and the centre of the sample started to dissipate its energy towards the tubes and the sample's core. The sample's core temperature was then increased. 
Figure 11 shows the numerical thermal map for specific vertical and horizontal sections at the beginning and end of each process. The vertical section was at a radius of $0 \mathrm{~mm}$, while the horizontal section was at a depth of $15 \mathrm{~cm}$. Figure 11 (a) and 11 (d) show the thermal map of the vertical and horizontal sections of the sample at the beginning of the charging process $(\mathrm{t}=0 \mathrm{hr}$.). Both figures show that the initial temperature distribution inside the concrete sample was homogenous and around $8.7^{\circ} \mathrm{C}$. The figures also show that the temperature of the heat exchanger tubes was slightly lower than the temperature of the concrete sample, to allow heat transfer from the sample to the HEX.

After $1 \frac{1 / 2}{h r}$., the charging process was terminated and the discharging process was initiated. Figure 11(b) and 11(e) show the thermal map of the aforementioned sections during this period. The figures represent the temperature variation inside the concrete sample, where the heat exchanger tubes were working as a heating element and the concrete sample was working as an energy storage medium up to this point. After this point, the situation was inverted and the heat exchanger tubes began extracting the energy stored in the sample. Figure 11 (c) and Figure 11 (f) show the same two sections at the end of the discharging process at which the temperature inside the concrete sample was around $13-15^{\circ} \mathrm{C}$. The difference between the temperature distribution at the beginning of the charging and the end of the discharging indicates that the amount of heat extracted was less than the amount of heat injected to the concrete, which leads to a decrease in storage efficiency, as shown in the storage efficiency calculation.

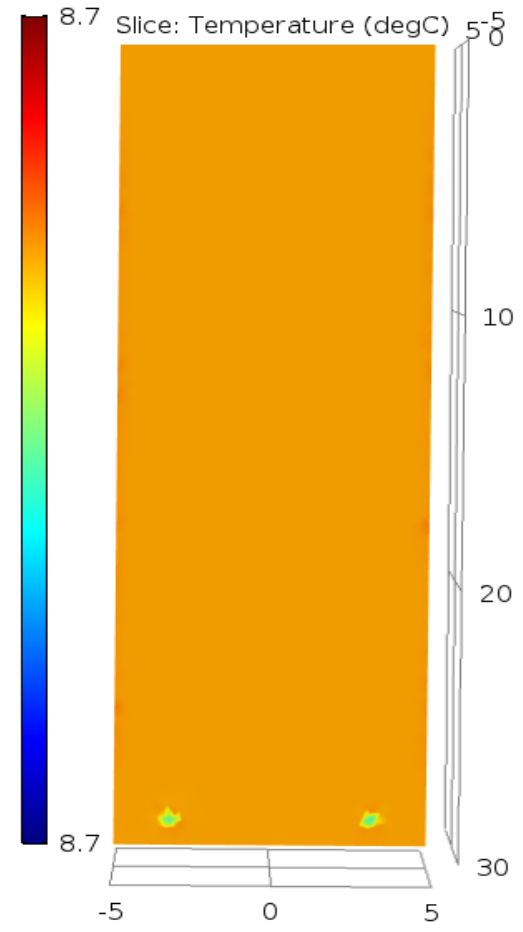

(a) Beginning of the charging process $(\mathrm{t}=0 \mathrm{hr})$

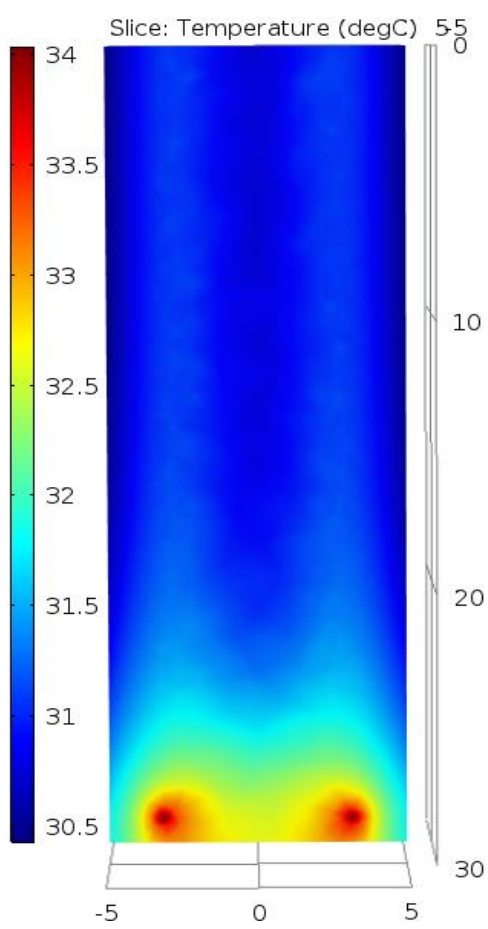

(b) End of the charging process $(\mathrm{t}=1.5 \mathrm{hr})$

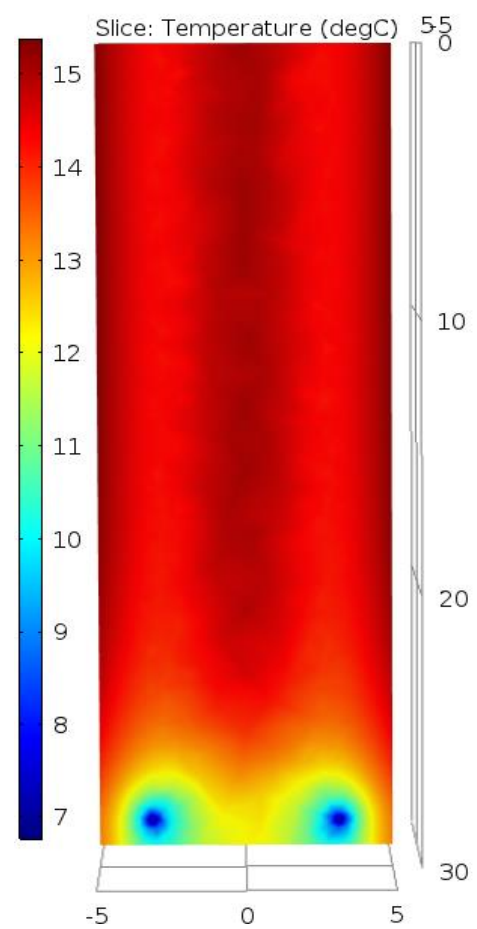

(c) End of the discharging process $(\mathrm{t}=3 \mathrm{hr})$ 


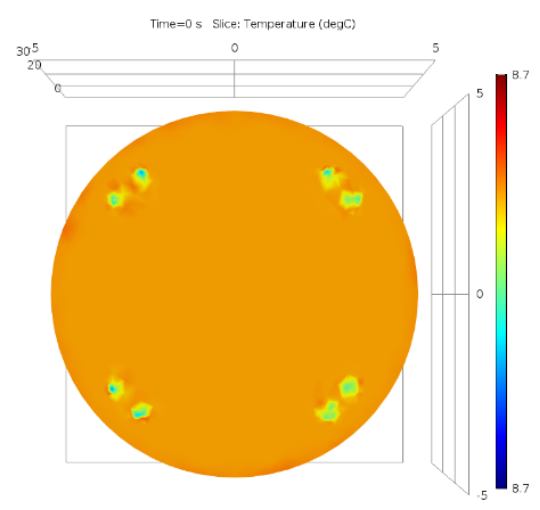

(d) Beginning of the charging process $(\mathrm{t}=0 \mathrm{hr})$

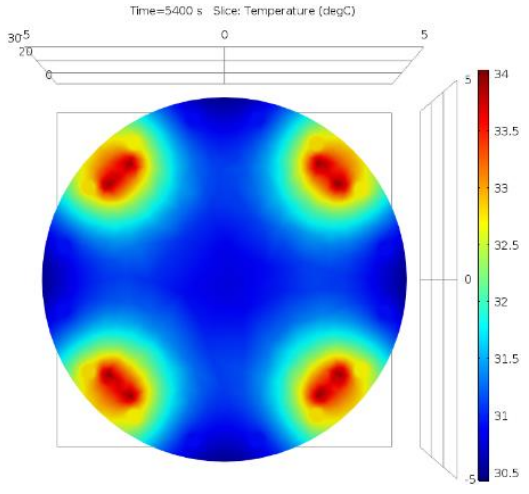

(e) End of the charging process $(\mathrm{t}=1.5 \mathrm{hr})$

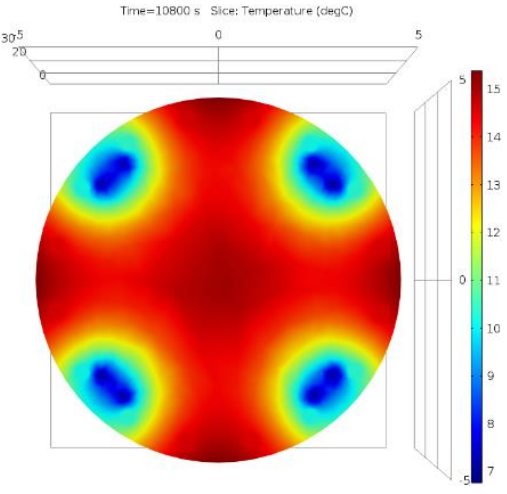

(f) End of the discharging process $(\mathrm{t}=3 \mathrm{hr})$

Figure 11: Thermal map for vertical and horizontal sections at the beginning and end of each process Q=1471 $\mathrm{ml} / \mathrm{min}$

\subsection{Ambient and surface temperature}

Figure 12 shows the variation of the surface and ambient temperatures during the charging and discharging processes. At the beginning of the charging process, the surface temperature was at its minimum value of $20.2^{\circ} \mathrm{C}$, which was lower than the ambient temperature. This difference was caused by the pre-cooling process. After the charging process moved forward, the surface temperature began to increase to reach its maximum value of $23.6^{\circ} \mathrm{C}$, while the ambient temperature stayed nearly steady at $22.5^{\circ} \mathrm{C}$. After the cooling process was initiated, the surface temperature began to slowly decrease. This figure proved that the insulation used for the concrete sample was efficient.

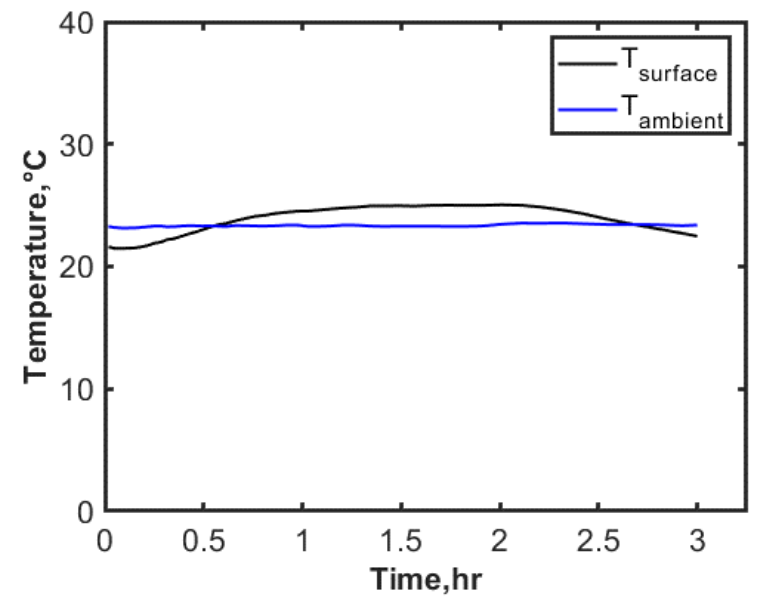

Figure 12: Insulation outer surface temperature with ambient temperature at $\mathrm{Q}=1471 \mathrm{ml} / \mathrm{min}$

\subsection{Effect of different flow rates}

To study the effect of different flow rates on the performance of the energy piles, turbulent and laminar flow rates were examined. As previously mentioned, the real flow rate of the working fluid inside the energy pile heat exchanger tubes is 3 gallons per minute for each 1 ton of refrigeration (according to heat pump manufacturer). For the same Reynolds number inside the sample, the calculated flow rate was $1471 \mathrm{ml} / \mathrm{min}$. The aim was to investigate half and double of this value $(735 \mathrm{ml} / \mathrm{min}$ and $2940 \mathrm{ml} / \mathrm{min}$, respectively). The maximum flow rate the water-bath could supply without using an external pump was $2100 \mathrm{ml} / \mathrm{min}$. This value was therefore used instead of $2940 \mathrm{ml} / \mathrm{min}$. 
Figure 13 shows the effect of different flow rates on the outlet temperature profile and the temperature difference between the inlet and outlet flow of each flow rate during the charging and discharging processes. Figure 13 (b) revealed that increasing the flow rate decreased the absolute temperature difference between the inlet and outlet. The figure also shows that increasing the flow rate from $735 \mathrm{ml} / \mathrm{min}$ to $1471 \mathrm{ml} / \mathrm{min}$ decreased the average temperature difference during charging and discharging by $51 \%$ and $63 \%$, respectively. While increasing the flow rate from $735 \mathrm{ml} / \mathrm{min}$ to $2100 \mathrm{ml} / \mathrm{min}$ decreased the average temperature difference during charging and discharging by $60 \%$ and $65 \%$, respectively. The figure also shows that at the beginning of the charging process the difference began to increase gradually, until the inlet water temperature reached its maximum value after around $1 / 2 \mathrm{hr}$., and then it started to decreases again till the end of the process.

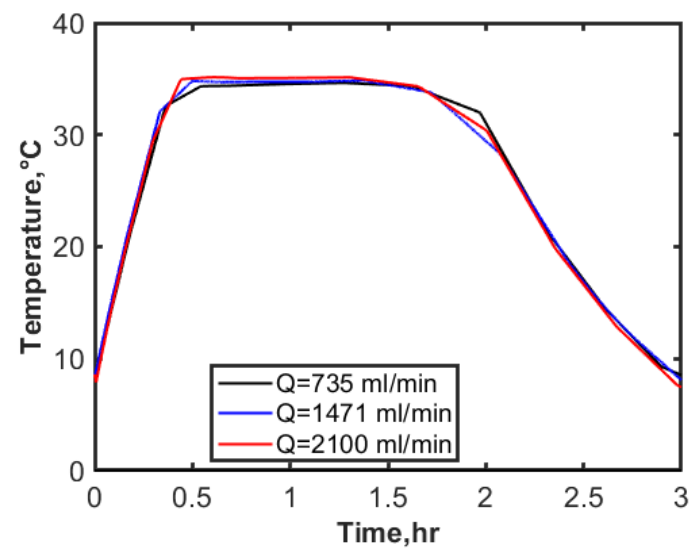

(a) Outlet water temperature

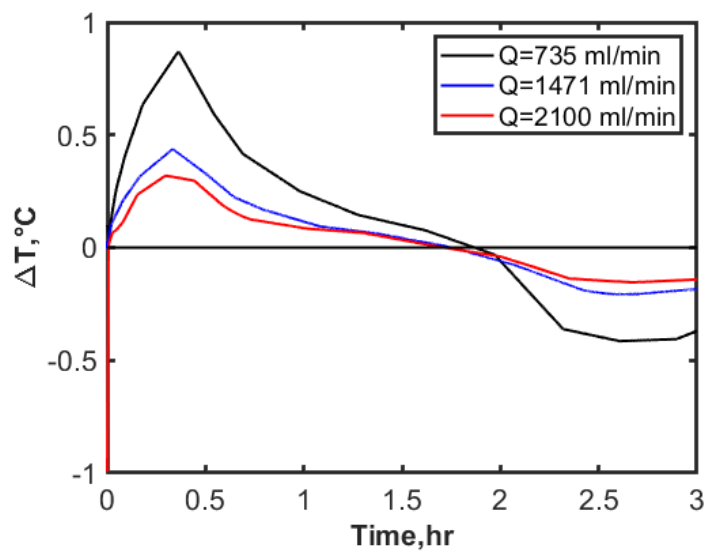

(b) Inlet and outlet water temperature difference

Figure 13: Effect of different flow rates on the outlet temperature profile

\subsection{Energy storage and storage efficiency}

In order to investigate the ability of the concrete piles to store and release energy, the amount of energy stored and extracted within the concrete sample boundaries was calculated during the charging and discharging processes. Figure 14 (a) showed the heat transfer rate from the wall of the HEX tubes throughout the experiment. For the flow rate of 735,1471 and $2100 \mathrm{ml} / \mathrm{min}$, the total amount of heat rejected was $16.56,16.86$ and $17.16 \mathrm{~kJ} / \mathrm{kg}$, respectively. While the amount of heat extracted was $12.5,12.9$ and 14.2 $\mathrm{kJ} / \mathrm{kg}$, respectively. Increasing the flow rate increased not only the amount of the heat rejected and extracted from the concrete but also the concrete storage efficiency, as increasing the flow rate inside the HEX tubes increased the heat transfer coefficient inside the tubes which increased the total amount of energy rejected during the same period of the charging process, the same trend occurred during the discharging process. The ratio between the heat add and extracted during the charging and discharging, respectively. The results also revealed that for the same charging and discharging time period, none of the flow rates could extract all of the heat stored in the sample. Not only does this affect the storage efficiency of the sample, it also increases the average underground temperature with each cycle since the energy that is removed will dissipate into the soil underground on the real case energy piles. The following table summarize the total internal energy at the beginning and end of each process, the total heat rejected and extracted and the storage efficiency with the different flow rates. 


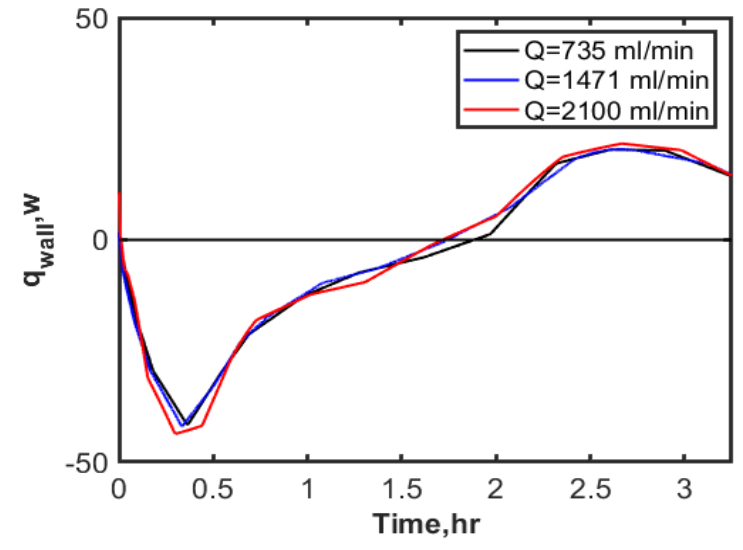

(a) Wall heat transfer rate of the HEX tubes

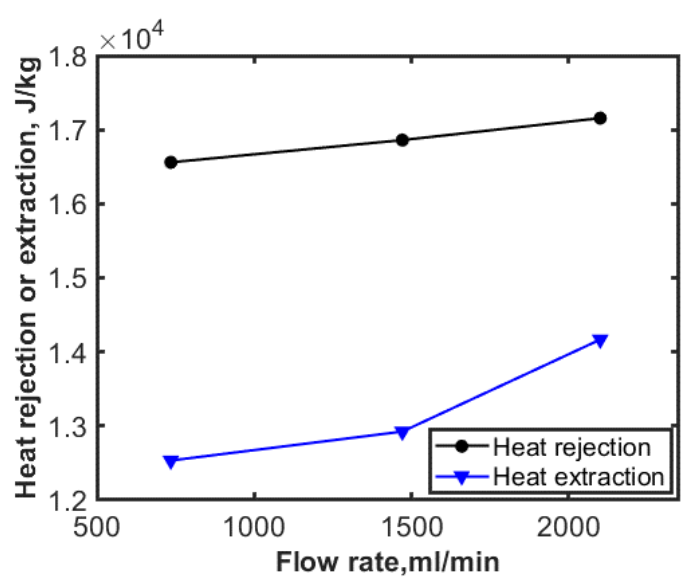

(b) Amount of heat rejection and extraction

Figure 14:Effect of flow rate on the amount of energy storage

Table 4: effect of flow rate on storage efficiency

\begin{tabular}{lccc}
\hline Flow rate $(\mathrm{ml} / \mathrm{min})$ & 735 & 1471 & 2100 \\
\hline Average initial temperature $\left({ }^{\circ} \mathrm{C}\right)$ & 8.69 & 8.68 & 8.66 \\
Percentage increase in mass flow rate & - & 100 & 185.7 \\
Total internal energy of concrete at the beginning of charging $(\mathrm{J} / \mathrm{kg})$ & -7857.3 & -7857.3 & -7857.3 \\
Total internal energy of concrete at the beginning of discharging $(\mathrm{J} / \mathrm{kg})$ & 8702 & 9002.5 & 9298.8 \\
Total internal energy of concrete at the end of discharging $(\mathrm{J} / \mathrm{kg})$ & -3832.3 & -3922.7 & -4868.6 \\
Total heat input during charging $(\mathrm{J} / \mathrm{kg})$ & 16559.3 & 16859.8 & 17156.1 \\
Total heat extracted during discharging $(\mathrm{J} / \mathrm{kg})$ & 12534.3 & 12925.2 & 14167.4 \\
Storage efficiency & 0.756 & 0.766 & 0.82 \\
\hline
\end{tabular}

\section{Conclusion}

A lab-scaled energy pile $(10 \mathrm{~cm}$ in diameter, $30 \mathrm{~cm}$ in length with a 4-U-loop heat exchanger) was created to experimentally and numerically investigate the thermal response of a concrete foundation pile to charging and discharging. The study also looked at the effect of different flow rates $(735,1471$ and $2100 \mathrm{ml} / \mathrm{min})$ on the performance of the energy pile. The following points summarize the results of the study:

- The Numerical predictions are inline with the experimental results on terms of the thermal response of the concrete, and the outlet water temperature profile during the charging and discharging processes for different flow rates.

- The numerical model could be used to predict the effect of different operating conditions (charging period, discharging period, maximum inlet water temperature, length of the energy pile, location of the heat exchanger, or the diameter of the heat exchanger tubes) to optimize the operating conditions of that energy pile sample without any experimental cost. 
- The numerical and experimental results showed the ability of the energy pile to store and release energy, which could be a solution for high energy consumption rates in the residential building sector. This could also be a suitable thermal storage medium for intermittent solar energy radiation.

- The investigation of different flow rates revealed that increasing the flow rate increases not only the amount of energy stored and released by the energy pile but also the storage efficiency of the system. For the flow rate of $735 \mathrm{ml} / \mathrm{min}, 1471 \mathrm{ml} / \mathrm{min}$, and $2100 \mathrm{ml} / \mathrm{min}$ the storage efficiency was found to be $75 \%, 76 \%$ and $82 \%$, respectively.

- The ratio of the heat extracted to the heat stored was less than unity at each flow rate, hence, the remaining part of this energy will dissipate into the nearby underground soil in the real case scenario, which will increase the average temperature of the underground soil.

\section{Acknowledgements}

The authors acknowledge the funding of this project by Ontario Center of Excellence, (OCE) National Science and Engineering Council Canada (NSERC), McClymont and Rak Engineers Inc and Qatar National Research Foundation (NPRP12S-0123-190011). 


\section{References}

[1] D. Gibb, M. Johnson, J. Romaní, J. Gasia, L. F. Cabeza, and A. Seitz, "Process integration of thermal energy storage systems - Evaluation methodology and case studies," Appl. Energy, vol. 230, pp. 750-760, Nov. 2018.

[2] Enviroment Canada, "No Title," 2019. [Online]. Available: https://www.canada.ca/en/environment-climate-change/services/environmentalindicators/progress-towards-canada-greenhouse-gas-emissions-reductiontarget.html\#targetText=Human activity increases the amount of GHG in the atmosphere.\&targetText=Under the Pari.

[3] S. A. Memon, "Phase change materials integrated in building walls: A state of the art review," Renewable and Sustainable Energy Reviews, vol. 31. Elsevier Ltd, pp. 870-906, 2014.

[4] J. Fadejev, R. Simson, J. Kurnitski, and F. Haghighat, "A review on energy piles design, sizing and modelling," Energy, vol. 122, pp. 390-407, 2017.

[5] J. W. Lund, D. H. Freeston, and T. L. Boyd, "Direct utilization of geothermal energy 2010 worldwide review," Geothermics, vol. 40, no. 3, pp. 159-180, 2011.

[6] H. Brandl, "Energy foundations and other thermo-active ground structures," Geotechnique, vol. 56, no. 2, pp. 81-122, 2006.

[7] F. M. Rad, A. S. Fung, and W. H. Leong, "Feasibility of combined solar thermal and ground source heat pump systems in cold climate, Canada," Energy Build., vol. 61, pp. 224-232, 2013.

[8] A. Minaei and M. Maerefat, "A new analytical model for short-term borehole heat exchanger based on thermal resistance capacity model," Energy Build., vol. 146, pp. 233242, Jul. 2017.

[9] F. M. Rad, A. S. Fung, and M. A. Rosen, "An integrated model for designing a solar community heating system with borehole thermal storage," Energy Sustain. Dev., vol. 36, pp. 6-15, Feb. 2017.

[10] F. M. Rad and A. S. Fung, "Solar community heating and cooling system with borehole thermal energy storage - Review of systems," Renewable and Sustainable Energy Reviews, vol. 60. Elsevier Ltd, pp. 1550-1561, 01-Jul-2016.

[11] E. Wang, A. S. Fung, C. Qi, and W. H. Leong, "Performance prediction of a hybrid solar ground-source heat pump system,” Energy Build., vol. 47, pp. 600-611, Apr. 2012.

[12] D. Pahud and M. Hubbuch, "Measured Thermal Performances of the Energy Pile System of the Dock Midfield at Zürich Airport," Procedding Eur. Geotherm. Congr. 2007, vol. 2, no. June, pp. 1-7, 2007.

[13] Y. Hamada, H. Saitoh, M. Nakamura, H. Kubota, and K. Ochifuji, "Field performance of an energy pile system for space heating," Energy Build., vol. 39, no. 5, pp. 517-524, May 2007. 
[14] Q. Zhao, B. Chen, M. Tian, and F. Liu, "Investigation on the thermal behavior of energy piles and borehole heat exchangers: A case study," Energy, vol. 162, pp. 787-797, Nov. 2018.

[15] J. Fadejev and J. Kurnitski, "Geothermal energy piles and boreholes design with heat pump in a whole building simulation software," Energy Build., vol. 106, pp. 23-34, 2015.

[16] S. You, X. Cheng, H. Guo, and Z. Yao, "In-situ experimental study of heat exchange capacity of CFG pile geothermal exchangers," Energy Build., vol. 79, pp. 23-31, 2014.

[17] J. Gao, X. Zhang, J. Liu, K. Li, and J. Yang, "Numerical and experimental assessment of thermal performance of vertical energy piles: An application," Appl. Energy, vol. 85, no. 10, pp. 901-910, 2008.

[18] S. Yoon, S. R. Lee, J. Xue, K. Zosseder, G. H. Go, and H. Park, "Evaluation of the thermal efficiency and a cost analysis of different types of ground heat exchangers in energy piles," Energy Convers. Manag., vol. 105, pp. 393-402, Aug. 2015.

[19] Jalaluddin, A. Miyara, K. Tsubaki, S. Inoue, and K. Yoshida, "Experimental study of several types of ground heat exchanger using a steel pile foundation," Renew. Energy, vol. 36, no. 2, pp. 764-771, Feb. 2011.

[20] J. Gao, X. Zhang, J. Liu, K. S. Li, and J. Yang, "Thermal performance and ground temperature of vertical pile-foundation heat exchangers: A case study," Appl. Therm. Eng., vol. 28, no. 17-18, pp. 2295-2304, Dec. 2008.

[21] C. J. Wood, H. Liu, and S. B. Riffat, "Comparative performance of 'U-tube' and 'coaxial' loop designs for use with a ground source heat pump," Appl. Therm. Eng., vol. 37, pp. 190-195, May 2012.

[22] Y. Hamada, H. Saitoh, M. Nakamura, H. Kubota, and K. Ochifuji, "Field performance of an energy pile system for space heating," Energy Build., vol. 39, no. 5, pp. 517-524, 2007.

[23] H. Park, S. R. Lee, S. Yoon, and J. C. Choi, "Evaluation of thermal response and performance of PHC energy pile: Field experiments and numerical simulation," Appl. Energy, vol. 103, pp. 12-24, 2013.

[24] A. Zarrella, M. De Carli, and A. Galgaro, "Thermal performance of two types of energy foundation pile: Helical pipe and triple U-tube," Appl. Therm. Eng., vol. 61, no. 2, pp. 301-310, 2013.

[25] F. Cecinato and F. A. Loveridge, "Influences on the thermal efficiency of energy piles," Energy, vol. 82, pp. 1021-1033, Mar. 2015.

[26] L. W. Williams, G. P.; Gold, “Ground temperatures," Canadian Building Digest, 1976. [Online]. Available: https://nrc-publications.canada.ca/eng/view/object/?id=386ddf88fe8d-45dd-aabb-0a55be826f3f.

[27] "Ground-Source Heat Pumps (Earth-Energy Systems)." [Online]. Available: https://www.nrcan.gc.ca/energy/publications/efficiency/heating-heat-pump/6833.

[28] J. R. Taylor, An Introduction to Error Analysis: The Study of Uncertainties in Physical 
Measurments. University Science Books, 648 Broadway, Suite 902, New York, NY 10012, 1997.

[29] "COMSOL Multiphysics, retrieved from http://www.comsol.com/comsol-multiphysics, March, 2015.”.

[30] J. E. Patterson and R. J. Miers, "The Thermal Conductivity of Common Tubing Materials Applied in a Solar Water Heater Collector," 46th ASC Annu. Int. Conf., 2010.

[31] D. Naldzhiev, D. Mumovic, and M. Strlic, "Polyurethane insulation and household products - A systematic review of their impact on indoor environmental quality," Build. Environ., vol. 169, p. 106559, 2020.

[32] D. P. Hochstein and C. Meyer, "Measurement and prediction of thermal conductivity of cement paste," ACI Mater. J., vol. 113, no. 3, pp. 317-322, 2016.

[33] J. P. Meyer, M. Everts, N. Coetzee, K. Grote, and M. Steyn, "Heat transfer coefficients of laminar, transitional, quasi-turbulent and turbulent flow in circular tubes," Int. Commun. Heat Mass Transf., vol. 105, no. April, pp. 84-106, 2019. 